\title{
Achievement Goal Structure and Type of Assistance Sought in an Undergraduate Classroom
}

\author{
Joan Giblin, Old Dominion University \\ Jill E. Stefaniak, Old Dominion University
}

\begin{abstract}
In the face of adversity, learners seek help when confronted with a gap in knowledge. Unsurprisingly, past research focused on the personal costs, burdens, and risks of asking for help. Researchers now identify adaptive helpseeking as a beneficial strategy for learning. This study explored whether instructors could successfully integrate mastery or performance achievement goal structures into undergraduate course assignments. The implications for integrating help seeking strategies in an online learning environment are discussed.
\end{abstract}

Keywords: help-seeking, goal structure, online learning

Despite decades of research, a comprehensive understanding of academic help seeking has remained elusive (Ames \& Lau, 1982; Newman, 1994; Karabenick \& Newman, 2009; Schworm \& Grubber, 2012). At its core, learners seek help to continue learning when confronted with a gap in knowledge or comprehension; it is persistence in the face of adversity. Historically, researchers from western cultures viewed seeking help as an undesirable trait that signified an abnormal dependence on others. Unsurprisingly, past research focused on the personal costs, burdens, and risks of asking for help. However, Nelson-LeGall (1985) identified adaptive/instrumental and executive academic helpseeking as two distinct processes (Nelson-LeGall, 1985). In adaptive help-seeking, the learner is motivated by a desire to master the material and requests hints and assistance. In executive help seeking, the student requests the answer without the desire to build competency or mastery. Researchers now identify adaptive help-seeking as a beneficial strategy for learning as it positively correlates to academic achievement, even when controlling for prior achievement (Ryan \& Shin, 2011).

Seeking help involves social, cognitive, and metacognitive processes, as it requires learners to not only employ self-monitoring and evaluation strategies, but also to interact with others to learn (Barnard-Brak, Lan \& Paton, 2010; Karabenick, 2004; Pintrich, 2002). An online or hybrid environment presents different oppor- tunities and challenges to the learner (Yu-Chang, YuHui, Mathews, Carr-Chellman, 2009; Schworm \& Gruber, 2012, Whipp \& Lorentiz, 2009). Traditional conceptualizations of academic help-seeking require learners to engage socially with another individual, adding a unique set of costs and benefits (Nelson-LeGall, 1984; Karabenick \& Newman, 2009). In a face-to faceenvironment, it is readily apparent who asks for assistance and what assistance is needed. In this context, learners reveal their failure to understand directly to their peers and to their instructor, which may carry fears of embarrassment, social risk and hinder help-seeking behavior (Ryan \& Pintrich, 1997; Ryan, Pintrich \& Midgley, 2001; Schworm \& Gruber, 2012). An online environment may influence help-seeking behavior by reducing the social costs of face to face help-seeking.

The focus of this study was to extend current research into help-seeking behavior by exploring whether an instructor can successfully craft an assignment with a mastery or performance achievement goal structure and whether this achievement goal structure influences help-seeking behavior. In addition, the study sought to explore whether the learning environment influences how learners engage in traditional helpseeking behavior as well as assistance through online means. 


\section{Literature Review}

Help-seeking is a complex phenomenon affected by a multitude of interacting factors. Some of these factors are internal to the learner, including personal characteristics, motivations and preferences. External factors include the environment and other's responses to helpseeking bids. Help-seeking has been studied for decades, yet as technology changes, the research on helpseeking in academic endeavors has not kept pace. Many, but not all, of the steps involved in seeking help deal with SRL and metacognitive activities, such as identifying comprehension gaps and selecting strategies. Only a few steps are directly related to the overt behavior of seeking help. Many help-seeking models have implicitly defined seeking help as requiring face-to -face interaction with another individual or require instantaneous feedback. These models do not take into account the advances in technology that have made online and hybrid learning environments ubiquitous in higher education. It appears there is a paucity of empirical studies available which focus on help-seeking behavior which occurs in the context of today's online world. However, as the largest threats to seeking help are social in nature, this results in a lack of understanding how learners seek assistance to persist in their learning endeavors.

\section{Help-Seeking Process}

Learners engage in help-seeking behavior to resolve a comprehension or knowledge gap (Nelson-LeGall, 1985). Help-seeking on its own is not beneficial, it is only when recognizing help-seeking as part of a strategy to persist through adversity in learning does the importance of help-seeking behavior become important (Newman, 1994). Help-seeking models recognize that learners make intentional decisions to seek help for a number of reasons. These decisions require significant metacognitive resources and active participation from the learner (Newman, 2002). Karabenick and Newman (2009) synthesized a number of models, including Nelson-LeGall's (1985) seminal conceptualization of helpseeking as the behavioral outcome of cognitive and metacognitive processes, driven by motivation. First, learners determine both that a gap or problem exists and then decide that help is needed. Learners become aware of a comprehension gap in a variety of ways, such as self-monitoring, comparing performance against internal goals, receiving feedback and/or other metacognitive activities. Simply recognizing that a gap in comprehension or an inability to perform an assignment exists does not automatically kick start the help seeking process (Mercier \& Fredericksen, 2007). Once learners recognize a gap exists, they may try other strategies, such as quitting, or immediately determine that seeking help is the most appropriate strategy (Karabenick \& Newman, 2009).

\section{Instructor Influence}

Contributing to any learning environment is the presence of the instructor. The learner's perception of instructor support also impacted whether or not a student perceived a classroom as mastery oriented in faceto-face environments. Karabenick (1994) assessed over 1000 undergraduate students' perceptions of instructor support for student questions during class and found these perceptions correlated with the learners' perception of the goal orientation of the classroom. When students believed that their questions signaled a "desire to learn" to their instructor rather than their inability to comprehend the material, they were more likely to view their classroom as mastery oriented (Karabenick, 1994, p. 199). Other studies provide similar results. For example, Kozanitis and colleagues (2007) measured selfreported help-seeking behavior and found that learners' perceptions of the instructor positively influenced adaptive help-seeking. The researchers theorized that the instructor's verbal and non-verbal communication can support help-seeking behavior. These studies also focused on semester-long face-to-face environments and measured traditional face-to-face help-seeking. While these studies did investigate a distinct component of help-seeking, the influence of the instructor, they did not drill down to determine what made the instructor appear to value the learner's questions. In addition, they did not address if a student sought to overcome comprehension gaps through other means, such as independent online searches, or if a hybrid environment might alter help-seeking behavior, where the verbal and non-verbal communication methods are mediated through a computer.

Few studies have examined help-seeking in an online or hybrid environment. However, the existing research in this area reinforces the instructor's influence on student help-seeking behavior. One study demonstrated that students who had high numbers of interactions with instructors perceived as providing academic and social support sought help most frequently in an online environment (Whipp \& Lorentz, 2009). While the study identified accessibility of the instructor as an important trait in help-seeking, the help requested was logistical and technical in nature. For example, students tended to contact the professor when issues with exams arose or when they had difficulty understanding an assignment prompt. The study did not investigate other avenues of seeking assistance with completing the course requirements.

\section{Technology and Help-Seeking}

While researchers have extensively studied helpseeking in a face-to-face environment, less attention has been paid to the online environment. The mediating effect of technology is important to consider when thinking about academic help-seeking. An online environment may ameliorate many of the threats and the social risks present in a face to face classroom (Kitsantas \& Chow, 2007; Schworm \& Gruber, 2012; Whipp \& Lorentz, 2009). Support for this hypothesis can be drawn from Kitsantas and Chow's (2007) study in which 472 undergraduate students were surveyed across four different types of instruction media: traditional, distributed, web with synchronous discussions and asynchronous only web-based classes to determine if the instructional medium impacted help-seeking from formal sources, such as their instructor. They found that students in the web-based sections sought help more frequently and felt less threatened to do so, whether or not they had synchronous elements to them. However, this study utilized 11 different instructors and three distinct content areas which aligned with the instructional medium, perhaps confounding the results. 
As previously noted, learning strategies can shift based on the domain, thus the alignment of discrete content areas with different delivery media may have influenced the results. A more thorough exploration of the potential of the environment to mitigate help-seeking barriers is necessary to further support these findings.

\section{Purpose}

The purpose of this study was to examine whether an instructor can intentionally craft a mastery or performance assignment and whether this will influence helpseeking behavior. Previous research relied on the learners' perception of the goal orientation of a semesterlong class without understanding how an instructor may deliberately influence this perception through factors under their control, such as assignments. In addition, few studies have investigated academic help seeking in an online or hybrid setting (Kitsantas \& Chow, 2007; Whipp \& Lorentz, 2009) and many of the threats that are typically associated with help-seeking may be diminished in an online environment. The following research questions guided this study:

1) Does the learner's perception of the achievement goal of an assignment match the intention of the instructor who created the assignment?

2) Does the classroom environment influence whether learners are more likely to seek help from a formal source, such as their instructor, or an informal source, such as their peers or online?

\section{Method}

\section{Research Design and Participants}

The study consisted of a mixed-methods quasiexperimental design and participants were recruited from a course with an enrollment of 60 students in three sections. A total of ten participants responded to a series of surveys exploring the effects that classroom environment had on help-seeking behavior. The students were enrolled in an undergraduate degree program at an urban university in the Mid-Atlantic region. The class was a general education course with students drawn from across the university. Participants who audited the class as well as students who had previously taken the course or withdrawn from the course previously were excluded from the study.

\section{Procedures}

A Web Quest and an Annotated Bibliography were used as two assignments for this study. The Web Quest assignment required students to simply find information using library research methods. The more complex Annotated Bibliography project required participants to locate and analyze primary and secondary source material, organize their research, create annotations summarizing and relating material to their topic of choice. Both assignments were graded by the instructors via a rubric

In both the hybrid and face-to-face sections of the class, participants were presented with identical assignment information in terms of content and expectations. However, half of each section of the class received the assignment embedded in a mastery-oriented context and half received an identical assignment em- bedded in a performance-based context. Participants were not aware of the treatment conditions. In the mastery-oriented treatment group, the instructions emphasized learning the material deeply and accurately. The performance treatment group received assignments emphasizing performance and grades as the primary goal. Students completed the assignments in their respective environments through the sixth week of the semester.

\section{Data Collection}

Data were collected following each assignment during the study. Participants responded to a survey provided to them by the instructors via a link in an email.

Scales. To assess the type of help-seeking, participants completed an adapted form of the computer science help seeking scales (Appendix A) (Pajares, Cheong and Oberman, 2004). This assessment measured instrumental (adaptive) and executive (nonadaptive) help-seeking. Pajares and his colleagues (2004) found an alpha co-efficient of .89 and .92 for these scales respectively. As noted by the authors, these scales can be adapted by researchers in domains other than computer science. The instrument used an 8-point Likert-type response scale ranging from definitely false to definitely true, with no descriptors in between. This scale was administered following the submission of each assignment.

To assess the learner's perception of the achievement goal structure of the assignment (Appendix B), the researchers adapted and utilized Elliot and McGregor (2001)'s personal goal achievement scale. As Karabenick (2004) successfully demonstrated, personal achievement goal scales can be successfully adapted to reflect the classroom environment rather than individual preferences. This can be accomplished through such phrases as "In this class, the teacher" and "In this class, it is important to..." (p.574). This scale was adapted to reflect the assignment, rather than the class using phrases such as, "On this assignment, the teacher..." and "On this assignment, it is important to:" This survey was administered following the submission of each assignment.

Survey. Students completed one survey (Appendix C) consisting of three questions, which reported the number of times they sought help from their peers as well as any other sources they sought help from. This survey was administered twice, once following the Web Quest assignment and once following the Annotated Bibliography assignment.

\section{Results}

\section{Frequency of Help-Seeking by Environment}

There were five participants in the mastery condition and five participants in the performance condition. On the Web Quest assignment, students sought help an average of 1.66 times, with a median of 1 , while on the Annotated Bibliography assignment students sought assistance an average of 3 times, with a median of 2 . An independent samples t-test was run to determine if there were differences in the type of help sought between the mastery and performance conditions. Across both the Web Quest and the Annotated Bibliography assign- 
ments, the mean for both conditions was 1.8 , with a standard deviation of .45 . No difference resulted from the treatment conditions. For the Annotated Bibliography assignment, $100 \%$ of the participants in the hybrid section sought help, while only $25 \%$ of the students in the face-to-face section sought help. However, Fisher's exact test yielded a non-significant result $(p=.4)$.

\section{Assignment Achievement Structure and Type of Help- Seeking}

Two scales were employed to measure adaptive and non-adaptive help-seeking behavior (Pajares et al. 2004). Each construct scale consisted of ten questions. Both scales had a high level of internal consistency as determined by a Cronbach's alpha of .96 for the adaptive scale and a Cronbach's alpha of .97 for the nonadaptive scale. In addition, one 12 item scale with four sub-scales assessed the perception of the achievement orientation of the assignment (Elliot \& McGregor, 2001).The Cronbach's alpha for the four sub-scales ranged from .86 to .67 .

The scales were administered after each assignment and analyzed separately. One-way ANOVAs were conducted to determine if the mastery condition resulted in a higher frequency of adaptive help-seeking behavior as predicted. See Table 2. For the Web Quest assignment, participants were divided into two conditions: mastery $(n=4)$ and performance $(n=5)$. The data was normally distributed as indicated by a Shapiro-Wilk's test ( $p$ $>.05)$ and there was homogeneity of variances as assessed by Levene's test for equality of variances ( $p$ $=.576)$. In this case, adaptive help-seeking was higher for the performance condition $(M=5.64, S D=1.84)$ than for the mastery condition $(M=4.83, S D=2.69)$, but the difference was not statistically significant $F(1,7)$ $=.293, p=.605$.

In the Annotated Bibliography assignment, the participants were divided into two conditions: mastery $(n=$ 2 ) and performance $(n=7)$. The data were normally distributed as indicated by a Shapiro-Wilk's test ( $p$ $>.05)$. There was one outlier which was left included as it did not affect the outcome of the analysis and ap- peared to be a true value, not a measurement or reporting error. There was homogeneity of variances as assessed by Levene's test for equality of variances ( $p$ $=.707)$. The mastery condition was more likely to report adaptive help-seeking behavior $(M=6.7, S D=$ 1.55) than the performance condition $(M=5.48, S D=$ $1.24)$, however, the results were not statistically significant $F(1,7)=1.39, p=.277$

In contrast, an ANOVA (Table 1) conducted to determine whether the assignment achievement structure influenced non-adaptive help-seeking behavior did yield statistically significant results on the Annotated Bibliography assignment. While students in the performance condition were more likely to report nonadaptive help-seeking behavior $(\mathrm{M}=3.09, \mathrm{SD}=2.16)$ than those in the mastery condition $(\mathrm{M}=1.75, \mathrm{SD}=$ $1.11)$, the results were not statistically significant, Welch's $F(1,6.2), \mathrm{p}=.273$.

For the Annotated Bibliography assignment, there were no outliers. Seeking non-adaptive help was statistically significantly different between the mastery condition $(\mathrm{M}=1.05, \mathrm{SD}=.06)$ and the performance condition $(\mathrm{M}=3.22$, $\mathrm{SD}=1.83)$, Welch's $F(1,5.07)=8.46$, p $=.033$ with students in the performance condition more likely to seek non-adaptive help than those in the mastery condition.

\section{Source of Help}

In the second research question we sought to explore the influence of the environment and goal orientation on the source of the help. For the Web Quest assignment, a chi test for association revealed a nonstatistically significant association between the orientation of the assignment and the source of help $\chi^{2}(1)$ $=.75, p=.39$. However, overall, $66 \%$ of the participants sought assistance online rather than from an individual known to them. For the Annotated Bibliography assignment, there was a similar result with a nonstatistically significant association with regard to treatment condition $\chi^{2}(1)=.75, p=.38$, and an overall higher frequency of seeking online help (66\%) rather than face-to-face assistance The data analysis for the

Table 1

Adaptive and Non-Adaptive Behavior by Assignment and Condition

\begin{tabular}{lccc|cc}
\hline & \multicolumn{3}{c}{ Web Quest } & \multicolumn{2}{c}{ Annotated Bibliography } \\
\cline { 2 - 6 } & Mastery $(\mathrm{n}=4)$ & Performance $(\mathrm{n}=5)$ & $F$ & Mastery $(\mathrm{n}=2)$ & Performance $(\mathrm{n}=7)$ \\
\hline Adaptive Help & $4.83(2.69)$ & $5.64(1.84)$ & .293 & $6.7(1.55)$ & $5.84(1.24)$ \\
Seeking & & & & $1.06(.06)$ & $3.22(1.83)$ \\
\hline Non-Adaptive & $1.75(1.11)$ & $3.09(2.16)$ & & $8.46^{*}$ \\
Help-Seeking & & & & \\
\hline$* p<03$ & & & & \\
\hline
\end{tabular}


hybrid environment showed no association between the hybrid section of the classes and whether they sought help from a professor or online $\chi^{2}(1)=.75, p=.38$ for the annotated bibliography assignment. No data were available for the Web Quest assignment.

\section{Discussion}

This study provided valuable insight for instructors and instructional designers who seek to facilitate adaptive help-seeking. Help-seeking is situated in selfregulated learning and influenced by the environment (Karabenick \& Dembo, 2011). Previous research has demonstrated that many factors may influence student help-seeking behavior, such as the perception of the instructor and the perceived achievement orientation of the class, but has not identified how learner perceptions may be influenced intentionally by the instructor (Karabenick, 2004; Kozanitis et al., 2007). Primarily, this study explored how one instructor-controlled environmental factor, the achievement goal orientation of assignments, influenced help-seeking. Research has demonstrated that environments perceived as masteryoriented by the learner positively influence adaptive help-seeking (Karabenick \& Dembo, 2011). For instructors and designers, the issue of how to create this mastery-oriented environment has largely been left largely unexplored. Assignments are one area which instructors control and can manipulate in the classroom. Other factors may include orienting students to acceptable questioning practices (i.e. hold questions until after the lecture) and scaffolding student self-monitoring of performance (Karabenick \& Dembo, 2011). Thus, in this study we aimed to test whether the manipulation of assignments impacted learner perceptions, and by extension, help-seeking behavior. This study extends the current research on help-seeking behavior by examining whether specific assignments/assignments may be embedded in an achievement goal structure to facilitate adaptive help-seeking.

The results from this case study suggest that embedding assignments in a designed mastery or performancebased context can influence help-seeking behavior. Specifically, in this study we found that an assignment embedded in an intentionally created performance context resulted in statistically significant non-adaptive helpseeking. Furthermore, the results also suggest that a mastery context may facilitate adaptive help-seeking. Task complexity may have also played a role as participants were more likely to be affected by the achievement goal structure of the assignment on more complex assignments, especially in the performance condition. Task difficulty has been identified as a factor that can affect help-seeking (Stahl \& Bromme, 2009). During this study, participants sought help more frequently on the more complex and difficult Annotated Bibliography assignment and less frequently on the simple Web Quest assignment. In addition, the less complex Web Quest assignment also resulted in the students in the performance condition seeking non-adaptive help, that is non-learning oriented help, at higher rates than did those in the mastery condition, but to a non-significant extent. These findings extend those of prior research which linked the learner's perception of the achievement goal structure of the class as a whole to helpseeking (Karabenick \& Dembo, 2011; Ryan, Gheen \&
Midgley, 1998) and suggest that the achievement goal structure of the assignment plays a role in this link.

The results suggest that a hybrid environment does influence help-seeking behavior, as $100 \%$ of those in the hybrid sections sought help with the Annotated Bibliography assignment compared with $25 \%$ of the participants in the face-to-face section. In this case, the hybrid section contained a significant online component and met face to face every other week. It is possible that the hybrid environment, with its lesser face-to-face contact, decreased the social threats to help-seeking that occur in a face-to-face classroom, allowing students to feel more confident and comfortable seeking help (Ryan et al., 2001).

Previous research has largely considered seeking help only in the face-to-face learning environments (Karabenick, 2004; Kozanitis et al., 2007) with few exceptions (Whipp \& Lorentz, 2009; Kitsantas \& Chow, 2007). In this study, the majority of those who sought assistance did so online $(66 \%)$ across both assignments. These results show a clear overall desire for learners to find information online rather than to ask a classmate or an instructor for help. The reasons for this are likely varied. These assignments required extensive online work through database and internet searches. In addition, seeking help in an online format reduces traditional barriers to seeking help, such as fear, shame and avoidance of appearing incompetent (Ryan et al., 2001). The increase in privacy available online may have resulted in participants preferring to search for assistance and help online rather than contacting a peer or the instructor.

Based on the results of this study, students prefer to seek help online rather than in-person. Therefore, it is possible that a mastery-oriented student may choose to seek adaptive, that is, learning oriented, assistance online. Recognizing this preference, instructors and instructional designers should consider providing learners with high-quality adaptive online resources to assist them in completing their assignments. If seeking help by contacting peers or instructors represents a barrier, then providing learners with privately available information in an on-demand format may facilitate helpseeking behavior and persistence in learning.

\section{Limitations and Future Research}

The limitations of this study are many and evident. The most glaring limitations of the study are sample size, the nature of the assignments and the nature of the class. The small sample size limited the amount of analysis and resulted in challenges in interpreting the results. Therefore, many of the findings presented above are based on non-statistically significant results, which, nonetheless, are consistent with previous research. Future research should seek to incorporate more direct observation such as faculty logbooks of helpseeking bids from students as well as a larger sample size.

In light of the results showing a clear preference for students to engage in assistance-seeking behaviors online rather than with individuals they know, this is an area that should be further explored. A more focused investigation into the motivations of the learner for 
seeking help or assistance online as well as whether they are seeking adaptive or non-adaptive help would contribute to our understanding of help-seeking and self -regulated learning.

\section{Conclusion}

Overall, the environment appeared to play a role in student help-seeking behavior. Participants sought help online more frequently than from individuals known to them, including the instructor, who would appear to be the most knowledgeable source for help. In addition, it appears that the achievement orientation of the assignment influenced help-seeking behavior. Creating a performance-oriented assignment may influence learners to seek non-adaptive help, which previous literature has linked with lower academic achievement than those who seek adaptive help. While many of the results of the analysis were not statistically significant, perhaps due to the small sample size, the results do demonstrate that the instructor's wording on individual assignments, especially if performance based, can influence helpseeking behavior. Future research should investigate whether behavior typically understood as informationseeking can be adaptive or non-adaptive. Finally, the link between help-seeking and assignment complexity should be explored further in the literature. The complexity of the assignment may be a contributing factor which influences how and why students seek assistance.

\section{Author Note}

Corresponding Author: Joan Giblin, Department of STEM Education and Professional Studies, Old Dominion University, Jgib1003@odu.edu.

\section{References}

Ames, R., \& Lau, S. (1982). An attributional analysis of student help-seeking in academic settings. Journal of Educational Psychology, 74(3), 414-23.

Barnard-Brak, L., Lan, W. Y., \& Paton, V. O. (2010). Profiles in self-regulated learning in the online learning environment. International Review of Research in Open and Distance Learning, 11(1), 61-80.

Byström, K., \& Järvelin, K. (1995). Assignment complexity affects information seeking and use. Information processing \& management, 31(2), 191-213.

Elliot, A. J., \& McGregor, H. A. (2001). A $2 \times 2$ achievement goal framework. Journal of personality and social psychology, 80(3), 501.

Karabenick, S., \& Newman, R. (2009). Seeking help: Generalizable self-regulatory process and socialcultural barometer. Contemporary Motivation Research: From Global to Local Perspectives, 2548.

Karabenick, S. A., \& Dembo, M. H. (2011). Understanding and facilitating self-regulated help seeking. New Directions for Teaching \& Learning, 2011(126), 33-43. doi:10.1002/t1.442.
Karabenick, S. A. (1994). Relation of perceived teacher support of student questioning to students' beliefs about teacher attributions for questioning and perceived classroom learning environment. Learning and Individual Differences, 6(2), 187-204. doi:10.1016/1041-6080(94)90009-4

Karabenick, S. A. (2003). Seeking help in large college classes: A person-centered approach. Contemporary Educational Psychology, 28(1), 37-58. doi:10.1016/S0361-476X(02) 00012-7

Karabenick, S. A. (2004). Perceived achievement goal structure and college student help seeking. Journal of Educational Psychology, 96(3), 569.

Keefer, J. A., \& Karabenick, S. A. (1998). Help seeking in the information age. Strategic Help Seeking: Implications for Learning and Teaching, , 219250.

Kitsantas, A., \& Chow, A. (2007). College students' perceived threat and preference for seeking help in traditional, distributed, and distance learning environments. Computers \& Education, 48(3), 383395. doi:10.1016/j.compedu.2005.01.008

Knapp, J. R., \& Karabenick, S. A. (1988). Incidence of formal and informal academic help-seeking in higher education. Journal of College Student Development,

Kozanitis, A., Desbiens, J., \& Chouinard, R. (2007). Perception of teacher support and reaction towards questioning: Its relation to instrumental helpseeking and motivation to learn. International Journal of Teaching and Learning in Higher Education, 19(3), 238-250.

Magnusson, J., \& Perry, R. P. (1992). Academic helpseeking in the university setting: The effects of motivational set, attributional style, and help source characteristics. Research in Higher Education, 33(2), 227-45.

Mercier, J., \& Frederiksen, C. H. (2007). Individual differences in graduate students' help-seeking process in using a computer coach in problem-based learning. Learning \& Instruction, 17(2), 184-203. doi:10.1016/j.learninstruc.2007.01.013

Nelson-Le Gall, S. (1985). Help-seeking behavior in learning. Review of Research in Education, 12, 55 -90 .

Newman, R. S. (1994). Adaptive help seeking: A strategy of self-regulated learning.

Newman, R. S. (2002). How self-regulated learners cope with academic difficulty: The role of adaptive help seeking. Theory into Practice, 41(2), 132 -38 .

Pajares, F., Cheong, Y. F., \& Oberman, P. (2004). Psychometric analysis of computer science helpseeking scales. Educational and Psychological Measurement, 64(3), 496-513. 
Pintrich, P. (2004). A conceptual framework for assessing motivation and self-regulated learning in college students. Educational Psychology Review, 16(4), 385-407. doi:10.1007/s10648-0040006-X

Pintrich, P. (2002). The development of academic self regulation: The role of cognitive and motivational factors. In A. Wigfield, \& J. Eccles

(Eds.), Development of achievement motivation (pp. 249). San Diego: Academic Press.

Pintrich, P. R. (2000b). Multiple goals, multiple pathways: The role of goal orientation in

learning and achievement. Journal of Educational Psychology, 92(3), 544-555.

doi:10.1037/0022-0663.92.3.544

Puustinen, M., \& Rouet, J. (2009). Learning with new technologies: Help seeking and information searching revisited. Computers \& Education, 53 (4), 1014-1019. doi:10.1016/ j.compedu.2008.07.002

Puustinen, M., Volckaert-Legrier, O., Coquin, D., \& Bernicot, J. (2009). An analysis of students' spontaneous computer-mediated help seeking: A step toward the design of ecologically valid supporting tools. Computers \& Education, 53(4), 1040-1047. doi:10.1016/j.compedu.2008.10.003

Ryan, A. M., \& Shin, H. (2011). Help-seeking tendencies during early adolescence: An examination of motivational correlates and consequences for achievement. Learning and Instruction, 21(2), 247 -256 .

Ryan, A. M., \& Pintrich, P. R. (1997). "Should I ask for help?" the role of motivation and attitudes in adolescents' help seeking in math class. Journal of Educational Psychology, 89(2), 329-341. doi:10.1037/0022-0663.89.2.329

Ryan, A. M., Gheen, M. H., \& Midgley, C. (1998). Why do some students avoid asking for help? An examination of the interplay among students' academic efficacy, teachers' social-emotional role, and the classroom goal structure. Journal of educational psychology, 90(3), 528.

Ryan, A. M., Pintrich, P. R., \& Midgley, C. (2001). Avoiding seeking help in the classroom: Who and why? Educational Psychology Review, 13(2), 93114.

Schworm, S., \& Gruber, H. (2012). E-learning in universities: Supporting help-seeking processes by instructional prompts. British Journal of Educational Technology, 43(2), 272-281.

Stahl, E., \& Bromme, R. (2009). Not everybody needs help to seek help: Surprising effects of metacognitive instructions to foster help-seeking in an online -learning environment. Computers \& Education, 53(4), 1020-1028. doi:10.1016/ j.compedu.2008.10.004
Webb, N. M., Ing, M., Kersting, N., \& Nemer, K. M. (2006). Help seeking in cooperative learning groups. Strategic Help Seeking: Implications for Learning and Teaching, , 45-115.

Webb, N. M., \& Mastergeorge, A. (2003). Promoting effective helping behavior in peer-directed groups. International Journal of Educational Research, 39(1), 73-97.

Whipp, J., \& Lorentz, R. (2009). Cognitive and social help giving in online teaching: An exploratory study. Educational Technology Research \& Development, 57(2), 169-192. doi:10.1007/s11423008-9104-7

Wolters, C. A. (1998). Self-regulated learning and college students' regulation of motivation. Journal of Educational Psychology, 90(2), 224.

Wolters, Christopher A., and Shirley L. Yu. "The Relation Between Goal Orientation And Students'." Learning \& Individual Differences 8.3 (1996): 211. Academic Search Premier. Web. 22 Apr. 2014.

Xie, I., \& Cool, C. (2009). Understanding help seeking within the context of searching digital libraries. Journal of the A merican Society for Information Science and Technology, 60(3), 477494.

Yu-Chang Hsu, Yu-Hui Ching, Mathews, J. P., \& CarrChellman, A. (2009). Undergraduate students' self-regulated learning experience in web-based learning environments Quarterly Review of Distance Education, 10 (2), 109-121.

Zimmerman, B. J. (1989). A social cognitive view of self regulated academic learning. Journal of Educational Psychology, 81(3), 329.

Zimmerman, B. J. (1990). Self-regulated learning and academic achievement: An overview. Educational Psychologist, 25(1), 3.

Zimmerman, B. J. (2008). Investigating self-regulation and motivation: Historical background,

methodological developments, and future prospects. American Educational Research

Journal, 45(1), 166-183. doi:10.3102/0002831207312909 


\section{Appendix A}

\section{Type of Help Sought Scale (Adaptive/Performance)}

This scale will be administered at the end of each assignment and will identify the type of help the learner the learner sought. Learners will select from an 8 point Likert type scale with the following instructions:

"Please use the following scale to answer the statements below. Circle the number that best describes how true or false each statement is for you in this class"

1 (definitely false) -8 (definitely true)

Adaptive

1. When I asked my professor for help, I preferred to be given hints or clues rather than the answer

2. When I asked my professor for help, I didn't want my professor to give away the whole answer

3. When I asked the professor for help with something I didn't understand, I asked the professor to explain it to me rather than just give me the answer

4. When I asked the professor for help in this class, I only wanted as much information as necessary to complete the work myself

5. When I asked my professor for help in understanding the material in this class, I preferred that the professor help me understand the general ideas rather than simply tell me the answer

6. When I asked a student for help in this class, I didn't want the student to give away the whole answer

7. When I asked a student for help in understanding the material in this class, I preferred that the student help me understand the general ideas rather than simply tell me the answer

8. When I asked a student for help in this class, I wanted to be helped to complete the work myself rather than simply tell me the answer.

9. When I asked a student for help in this class, I preferred to be given hints and clues rather than the answer

10. When I asked a student for help with something I don't understand, I asked the student to explain it to me rather than just give the answer.

\section{Executive}

1. When I asked the professor for help in this class, I preferred that the professor do the work for me rather than explain to me how to do it.

2. When I asked the professor for help on something I don't understand, I preferred the teacher do it for me.

3. When I asked the professor for help on something I don't understand, I preferred to be given the answer rather than an explanation of how to do the work myself

4. When I asked the teacher for help with my work, I preferred the professor just give me the answer rather than explain it.

5. When I asked the professor for help, I wanted the teacher to do the work for me rather than help me be able to complete the work myself

6. When I asked a student for help on something, I didn't understand, I preferred the student to just give me the answer rather than to explain it

7. When I asked a student for help with my work, I preferred that the student do the work for me rather than explain to me how to do it

8. When I asked another student for help on something I don't understand, I asked that the student do it for me

9. When I asked a student for help in this class, I wanted the work done for me rather than be helped to complete the work myself

10. When I asked a student for help with my work, I preferred to be given the answer rather than an explanation of how to do the work myself.

Adapted from Parajes et al. (2004) 


\section{Appendix B}

\section{Perception of Assignment Goal Structure}

This scale will be administered at the end of the semester and will be used to determine the learners' perception of the goal orientation of the assignment. Learners will select from a 7 point scale with the following instructions:

"Please use the following scale to answer the statements below. Circle the number that best describes how true or false each statement about this class."

Scale: 1 (not at all true of this class) - 7 (very true of this class)

"Please use the following scale to answer the statements below. Circle the number that best describes how true or false each statement is for you."

1 (not at all true of me) - 7 (very true of me)

1. On this assignment, it is important for me to do better than other students

2. On this assignment, the teacher stresses that it is important for me to do well compared to others in this class

3. On this assignment, it is important to get a better grade than most of the other students

4. The teacher stresses On this assignment to learn as much as possible

5. On this assignment, it is important to learn the content as thoroughly as possible.

6. On this assignment, it is important to master the material

7. On this assignment, it is important not to do worse than other students

8. It is important $\mathrm{On}$ this assignment to not do poorly

9. On this assignment, the teacher stresses to avoid performing poorly compared to other students.

Adapted from Elliot and McGregor (2001) 


\section{Appendix C}

\section{Help-Seeking Preference Survey}

This survey will be a self-report instrument where students indicate whether or not they sought help and from whom they sought that help from. Learners will select from a pull-down menu with the following instructions:

"Please select the answer that best represents your behavior this week in this class:"

1. Did you seek help for this assignment?

- Yes

- No

2. Did you ask anyone for help with this assignment?

- Yes

- No

3. From whom did you seek help?

- The professor

- A fellow student in this class

- A fellow student outside of this class

- I looked online

- Where?

- Other: 